\title{
Switching Antipsychotics to Blonanserin in Patients with Schizophrenia: An Open-label, Prospective, Multicenter Study
}

\author{
Young Sup Woo ${ }^{1}$, Bo-Hyun Yoon ${ }^{2}$, Bong-Hee Jeon ${ }^{2}$, Jeong Seok Seo ${ }^{3}$, Beomwoo Nam ${ }^{3}$, Sang-Yeol Lee ${ }^{4}$ \\ Young-Myo Jae ${ }^{5}$, Sae-Heon Jang ${ }^{5}$, Hun Jeong Eun ${ }^{6}$, Seung-Hee Won ${ }^{7}$, Kwanghun Lee ${ }^{8}$, Jonghun Lee \\ Won-Myong Bahk'
}

${ }^{1}$ Department of Psychiatry, College of Medicine, The Catholic University of Korea, Seoul, ${ }^{2}$ Department of Psychiatry, Naju National Hospital, Naju, ${ }^{3}$ Department of Psychiatry, Konkuk University School of Medicine, Chungju, ${ }^{4}$ Department of Psychiatry, Wonkwang University School of Medicine, Iksan, ${ }^{5}$ Department of Psychiatry, Bongseng Memorial Hospital, Busan, ${ }^{6}$ Department of Neuropsychiatry, Presbyterian Medical Center-Jesus Hospital, Jeonju, ${ }^{7}$ Department of Psychiatry, School of Medicine, Kyungpook National University, Daegu, ${ }^{8}$ Department of Psychiatry, College of Medicine, Dongguk University, Gyeongju, ${ }^{9}$ Department of Psychiatry, School of Medicine, Catholic University of Daegu, Daegu, Korea

\begin{abstract}
Objective: This study was performed to investigate the efficacy and tolerability of blonanserin in schizophrenic patients who were previously treated with other antipsychotics but, due to insufficient response, were switched to blonanserin. Methods: A total of 52 patients with schizophrenia who were unresponsive to treatment with antipsychotic monotherapy or combination therapy were recruited into this 12-week, open-label, prospective, multicenter study. Patients were switched to blonanserin from their existing antipsychotics over a maximum 2-week tapering-off period. Efficacy was primarily evaluated using the 18-item Brief Psychiatric Rating Scale (BPRS). Assessments were performed at baseline, and at weeks 1, 2, 4, 8, and 12 .

Results: Switching to blonanserin resulted in a significant decrease in the mean total score on the BPRS from baseline $(56.8 \pm 9.4)$ to week $12(42.1 \pm 13.8, p<0.001)$. The most common adverse events were extrapyramidal symptoms $(\mathrm{n}=12,23.1 \%)$, insomnia $(\mathrm{n}=10,19.2 \%)$, and emotional arousal $(\mathrm{n}=6,11.5 \%)$. Overweight or obese patients (body mass index $\geq 23 \mathrm{~kg} / \mathrm{m}^{2}, \mathrm{n}=33$ ) who switched to blonanserin exhibited significant weight loss from $75.2 \pm$ $9.3 \mathrm{~kg}$ at baseline to $73.5 \pm 9.2 \mathrm{~kg}$ at week $12(p=0.006)$. The total cholesterol (baseline, $236.1 \pm 47.6 \mathrm{mg} / \mathrm{dl}$; endpoint [week 12], $209.9 \pm 28.0 \mathrm{mg} / \mathrm{dl} ; p=0.005$ ) and prolactin levels (baseline, $80.0 \pm 85.2 \mathrm{ng} / \mathrm{ml}$; endpoint [week 12], $63.2 \pm 88.9 \mathrm{ng} / \mathrm{ml} ; p=0.003$ ) were also significantly improved in patients with hypercholesterolemia or hyperprolactinemia.

Conclusion: The results of the present study suggest that switching to blonanserin may be an effective strategy for schizophrenic patients unresponsive to other antipsychotic treatments.
\end{abstract}

KEY WORDS: Blonanserin; Treatment outcome; Prolactin; Body weight.

\section{INTRODUCTION}

Received: October 23, 2018/ Revised: October 25, 2018

Accepted: October 26, 2018

Address for correspondence: Bo-Hyun Yoon

Department of Psychiatry, Naju National Hospital, 1328-31

Senam-ro, Sanpo-myeon, Naju 58213, Korea

E-mail: yoonbh@chollian.net

ORCID: https://orcid.org/0000-0002-3882-7930

Won-Myong Bahk

Department of Psychiatry, Yeouido St. Mary's Hospital, College of

Medicine, The Catholic University of Korea, 10 63-ro,

Yeongdeungpo-gu, Seoul 07345, Korea

E-mail:wmbahk@catholic.ac.kr

ORCID: https://orcid.org/0000-0002-0156-2510
Schizophrenia is a mental disorder characterized by behavioral, social, and cognitive deficits with a chronic and disabling course that commonly requires life-long therapeutic intervention. ${ }^{1,2)}$ Although atypical antipsychotics (AAP) are considered the cornerstone of schizophrenia treatment, the effect of these treatments is limited by unfavorable side effects, poor response to medication, and modest efficacy on negative symptoms. ${ }^{3)}$ Up to $70 \%$ of schizophrenic patients do not achieve full remission even with optimized antipsychotic treatment. ${ }^{4)}$ When pa-

(ㄷ) This is an Open-Access article distributed under the terms of the Creative Commons Attribution Non-Commercial License (http://creativecommons.org/licenses/by-nc/4.0) which permits unrestricted non-commercial use, distribution, and reproduction in any medium, provided the original work is properly cited. 
tients fail to respond to an antipsychotic, switching to another antipsychotic agent should be considered. ${ }^{5)}$ However, as all antipsychotics have advantages and disadvantages, it is difficult to determine whether one is better than the others in treatment decision making, and there is still controversy regarding which antipsychotics are preferable. Previous studies have recommended that the choice of antipsychotic medication should take into account the likely benefits and possible side effects of each drug, including metabolic, extrapyramidal, cardiovascular, and hormonal side effects. ${ }^{6)}$

Blonanserin is a second-generation antipsychotic commonly used in Japan and Korea with a unique pharmacological profile. It has higher dopamine D2 receptor occupancy $\left(K_{i}=0.142 \mathrm{nM}\right)$ and lower serotonin $2 \mathrm{~A}$ receptorblocking activity $\left(\mathrm{K}_{\mathrm{i}}=0.812 \mathrm{nM}\right)$ than those of other second-generation antipsychotic agents. ${ }^{7)}$ It also has weak dopamine D1 adrenergic alpha 1 receptor blocking activity. ${ }^{8)}$ The effectiveness of blonanserin in the treatment of schizophrenia has been demonstrated by double-blind, randomized trials, ${ }^{9-12)}$ a combination trial, ${ }_{1}^{13)}$ and a metaanalysis. ${ }^{14)}$ Blonanserin was found to be comparable in efficacy with other antipsychotics, according to the Positive and Negative Syndrome Scale total score; positive, negative, and general psychopathology subscale scores; and response rate. ${ }^{14)}$ Moreover, blonanserin is generally well tolerated with low risk of causing cardiovascular or metabolic side effects or hyperprolactinemia, ${ }^{8)}$ and it showed a lower rate of discontinuation due to intolerance compared with other AAPs, including quetiapine, aripiprazole, risperidone, and olanzapine. ${ }^{15)}$ Schizophrenia is associated with an increased risk of metabolic disorders, which can negatively influence mortality and morbidity, ${ }^{16)}$ and these adverse events (AEs) are among the most important reasons for switching from one antipsychotic to another ${ }^{17,18)}$; consequently, blonanserin may be an alternative option for patients who need to switch antipsychotic drugs due to insufficient efficacy or intolerability.

However, no studies have evaluated switching from other antipsychotics to blonanserin. The goal of this study was to test the hypothesis that switching from other antipsychotics to blonanserin will improve psychotic symptoms, and blonanserin will be well tolerated in patients who show an in sufficient response to other antipsychotics.

\section{METHODS}

\section{Study Design and Subjects}

This was an open-label, prospective, multicenter, 12-week study that included 52 patients. This study was conducted at seven centers in Korea, consisting of six university/general hospitals and one psychiatric hospital. The patients were 20 to 60 years old and diagnosed with schizophrenia according to the Diagnostic and Statistical Manual of Mental Disorders, fourth edition, text revision. Subjects had been receiving one or more antipsychotics other than blonanserin at an adequate dose for more than 2 weeks before enrollment. Subjects showing an insufficient response to antipsychotics, defined as continued evidence of at least moderately severe illness (18-item Korean version of the Brief Psychiatric Rating Scale [BPRS] score $>45$ ) after a minimum of 2 weeks of treatment, were included in the study.

Patients considered being at risk of suicide or homicide and women who were pregnant, lactating, or not using a reliable form of birth control were excluded from the study. Individuals with medical conditions that could interfere with daily life activities, a diagnosis of any Axis I disorder other than schizophrenia, mental retardation, or current or a history of neurological disease were also excluded. In addition, patients treated with clozapine or long-acting injectable antipsychotics within 6 months of the study or with antidepressants, mood stabilizers, or anticonvulsants within 1 month of the study, those currently being treated with lipid-lowering medications, and those known to be resistant to treatment were excluded. All subjects provided informed consent before participation in the study.

It is recommended that blonanserin is started at 4 $\mathrm{mg} /$ day and dosed flexibly from 8 to $24 \mathrm{mg} /$ day at the discretion of the investigator. The previously used antipsychotic agent was cross-tapered by gradually tapering during the first 2 weeks of the study period. Patients were not given any other antipsychotics, mood stabilizers/anticonvulsants, antidepressants, lipid-lowering medications, or strong CYP3A4 inhibitors during the study. Benzodiazepines could be given at doses of up to $4 \mathrm{mg}$ /day to treat anxiety or agitation. Anti-parkinsonian agents and propranolol were permitted to treat extrapyramidal symptoms (EPS) or akathisia but were not to be administered prophylactically. Hypnotics other than trazodone were 
permitted at the discretion of the investigator.

\section{Measurements}

Efficacy was evaluated at baseline and at weeks 1, 2, 4, 8 , and 12 . The primary assessment of efficacy was the mean change in the BPRS total score from baseline to week 12. Additional efficacy measures included mean changes in the Clinical Global Impression-Severity score and each item score on the BPRS, and the response rate evaluated using the BPRS. Response was defined as a $\geq 30 \%$ decrease in the BPRS total score. Functional status was evaluated using the Social and Occupational Functioning Assessment Scale (SOFAS). To assess the subjective effects of antipsychotics, the Subjective Wellbeing under Neuroleptic Treatment Scale short form (SWN) ${ }^{19)}$ and Drug Attitude Inventory-10 ${ }^{20)}$ were performed at baseline and at weeks 4, 8, and 12 .

Safety assessments included monitoring vital signs, body weight (BW), and body mass index (BMI); a physical examination; AE self-reporting; and scores on the Simpson-Angus Scale, Barnes Akathisia Rating Scale, and Abnormal Involuntary Movement Scale at each visit. Laboratory tests to assess fasting glucose (fasting blood sugar, FBS), total cholesterol (TC), fasting triglyceride (TG), high-density lipoprotein cholesterol, low-density lipoprotein cholesterol, glycated hemoglobin (HbA1c), and prolactin levels were performed at baseline and at week 12.

\section{Statistical Analysis}

Statistical analyses were performed based on an intent-to-treat analysis, and the data included all patients for whom a baseline and at least one post-baseline measurement were available. The last-observation-carried forward method was applied for endpoint analysis. All subjects who received at least one dose of the study medication were included in the safety analysis.

Categorical variables are presented as absolute numbers and relative frequencies (\%) and nominal variables as means and standard deviations. Scores on each psychometric scale and $\mathrm{AE}$ scale were analyzed by the Mann-Whitney $U$ test, paired $t$ test, and repeated measures analysis of variance (RM-ANOVA). The GreenhouseGeisser correction was used to test for non-sphericity in RM-ANOVA. The chi-square test or Fisher's exact test was used to analyze categorical variables. We also inves- tigated predictors of the response to blonanserin switching by comparing responders ( $\geq 50 \%$ decrease in the BPRS total score at week 12) and non-responders using the independent $t$ test, chi-square test, or Fisher's exact test. Binary logistic regression analysis was conducted, with age, sex, and variables trending toward significance $(p<0.10)$ in univariate analyses, using response as an independent variable (i.e., responders and non-responders). All statistical tests were two-tailed with a significance level of 0.05. All statistical analyses were conducted using the Statistical Analysis System software package (SAS, version 9.1; SAS Institute, Inc., Cary, NC, USA).

\section{Ethics}

The study was conducted in accordance with the Declaration of Helsinki and Good Clinical Practices. Written informed consent was obtained from all subjects after they had been given an extensive explanation of the nature and procedures of the study. The study protocol was approved by the institutional review or ethics committees at each study site.

\section{RESULTS}

\section{Patients and Medications}

A total of 52 patients were included in the study. The demographic and clinical characteristics of the subjects are presented in Table 1. Twenty-three patients (44.2\%) were treated with a combination of two or more antipsy-

Table 1. Demographics and clinical characteristics at baseline

\begin{tabular}{lc}
\hline \multicolumn{1}{c}{ Characteristic } & Data $(\mathrm{n}=52)$ \\
\hline Age $(\mathrm{yr})$ & $46.4 \pm 9.9$ \\
Sex, female & $20(38.5)$ \\
Age of onset (yr) & $29.7 \pm 10.0$ \\
Duration of illness (yr) & $16.6 \pm 9.2$ \\
Total number of hospitalizations & $4.4 \pm 4.3$ \\
Previous antipsychotics treatment & \\
Monotherapy & $29(54.9)$ \\
$\quad$ Chlorpromazine equivalent dose (mg/day) & $788.6 \pm 433.3$ \\
Baseline scores & \\
CGl-S & $4.1 \pm 0.7$ \\
BPRS & $56.8 \pm 9.4$ \\
SOFAS & $39.0 \pm 10.0$ \\
\hline
\end{tabular}

Values are presented as mean \pm standard deviation or number $(\%)$. CGI-S, Clinical Global Impression-Severity; BPRS, Brief Psychiatric Rating Scale; SOFAS, Social and Occupational Functioning Assessment Scale. 
chotics. The antipsychotics previously used were risperidone ( $n=31,59.6 \%)$, olanzapine ( $n=12,23.1 \%)$, quetiapine $(n=11,21.2 \%)$, haloperidol $(n=10,19.2 \%)$, aripiprazole ( $n=6,11.5 \%)$, amisulpride ( $n=4,7.7 \%$ ), chlorpromazine $(n=4,7.7 \%)$, paliperidone $(n=2,3.8 \%)$, ziprasidone ( $n=1,1.9 \%)$, and zotepine $(n=1,1.9 \%)$. The mean chlorpromazine equivalent dose $^{21)}$ of these previously used antipsychotics was $773.4 \pm 442.7 \mathrm{mg} /$ day at baseline. The mean dose of blonanserin during the entire study period was $17.3 \pm 5.2 \mathrm{mg} /$ day, and those at weeks 1 , $2,4,8$, and 12 were $7.3 \pm 4.5 \mathrm{mg} /$ day, $15.6 \pm 7.0 \mathrm{mg} /$ day, $16.5 \pm 6.4 \mathrm{mg} /$ day, $17.4 \pm 6.6 \mathrm{mg} /$ day, and $22.1 \pm 9.3$ $\mathrm{mg} /$ day, respectively. Thirty-two $(61.5 \%)$ patients were treated with benzodiazepines during the study period.

The mean total score on the BPRS decreased significantly from baseline $(56.8 \pm 9.4)$ to week $12(42.1 \pm$ 13.8, $p<0.001$ ) (Fig. 1). The difference was significant from week 1 (all $p<0.001$ ). The Clinical Global Impression-Severity score decreased from $4.1 \pm 0.7$ at baseline

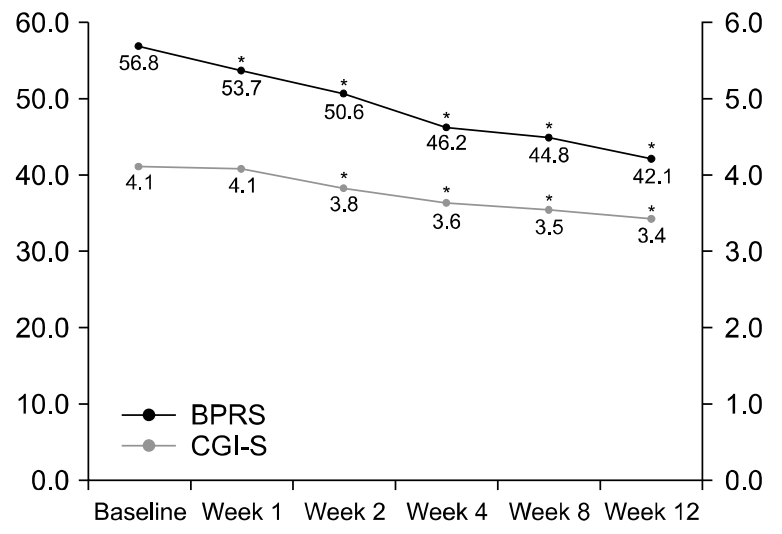

Fig. 1. Changes from baseline to week 12 in Brief Psychiatric Rating Scale (BPRS) and Clinical Global Impression-Severity (CGI-S) score. $* p<0.05$ compared to baseline. (defined as "moderately ill") to $3.4 \pm 1.0$ (defined as “mildly ill”) (Fig. 1). The number of responders who showed $\mathrm{a} \geq 30 \%$ reduction in the BPRS score from baseline to week 12 was 23 (44.2\%) (Fig. 2). The social functioning, as measured using the SOFAS, and subjective well-being, measured using the SWN, of the patients significantly improved from $39.1 \pm 9.8$ at baseline to $45.8 \pm$ 8.4 at week $12(p<0.001)$ and from $69.7 \pm 14.1$ at baseline to $76.7 \pm 13.8$ at week $12(p<0.001)$, respectively. The attitude toward medication, as measured using the Drug Attitude Inventory-10, also changed significantly during the study period ( $p=0.019$; Table 2). Table 3 shows a comparison of the characteristics between responders and non-responders. The mean dose of blonanserin used during the study period was significantly higher in responders $(20.4 \pm 3.7 \mathrm{mg} /$ day $)$ than non-responders $(14.7 \pm 4.9 \mathrm{mg} /$ day $)$. The rate of taking a blonanserin dose higher than the maintenance dose (high-dose group, $>16 \mathrm{mg} /$ day) was significantly higher $(95.7 \%, \mathrm{n}=22)$ among responders than non-responders

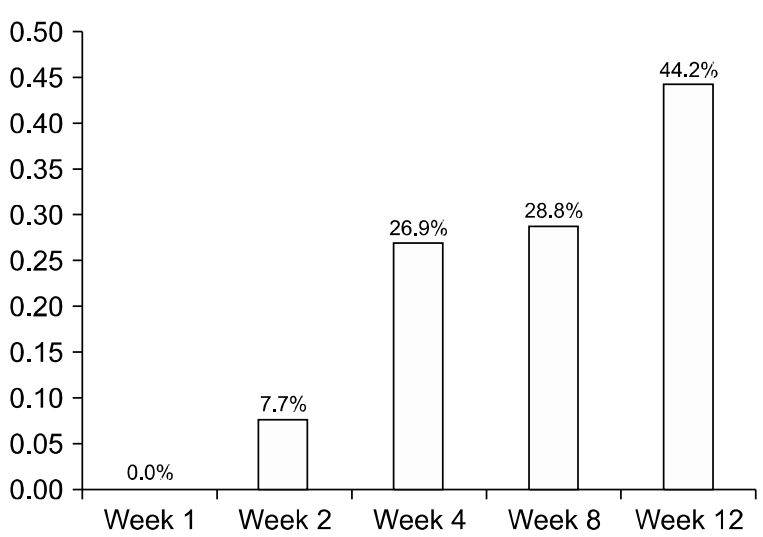

Fig. 2. Response rate ( $\geq 30 \%$ decrease compared to baseline score) in Brief Psychiatric Rating Scale total score.

Table 2. Changes in SOFAS, DAI-10, SWN, AIMS, SAS and BARS scores from baseline to week 12

\begin{tabular}{|c|c|c|c|c|c|c|c|c|}
\hline Scale & Baseline & Week 1 & Week 2 & Week 4 & Week 8 & Week 12 & $F$ value & Significance \\
\hline SOFAS & $39.1 \pm 9.8$ & $39.9 \pm 10.6$ & $41.9 \pm 8.2$ & $43.2 \pm 7.7$ & $44.3 \pm 7.5$ & $45.8 \pm 8.4$ & 13.440 & $<0.001$ \\
\hline DAI-10 & $5.3 \pm 2.5$ & - & - & $5.5 \pm 2.2$ & $6.1 \pm 2.3$ & $5.9 \pm 2.2$ & 3.434 & 0.019 \\
\hline SWN & $69.7 \pm 14.1$ & - & - & $71.8 \pm 14.5$ & $73.6 \pm 13.5$ & $76.7 \pm 13.8$ & 7.523 & $<0.001$ \\
\hline AIMS & $2.2 \pm 3.4$ & $2.5 \pm 3.6$ & $3.0 \pm 4.3$ & $2.9 \pm 4.4$ & $2.8 \pm 3.9$ & $2.6 \pm 3.9$ & 1.623 & 0.154 \\
\hline SAS & $2.0 \pm 2.2$ & $2.1 \pm 2.3$ & $2.7 \pm 4.2$ & $2.3 \pm 2.7$ & $2.1 \pm 2.3$ & $2.0 \pm 2.3$ & 1.340 & 0.248 \\
\hline BARS & $0.6 \pm 1.3$ & $1.0 \pm 1.9$ & $1.0 \pm 2.1$ & $0.9 \pm 1.7$ & $1.0 \pm 1.8$ & $0.8 \pm 1.5$ & 0.906 & 0.477 \\
\hline
\end{tabular}

Values are presented as mean \pm standard deviation.

SOFAS, Social and Occupational Functioning Assessment Scale; DAI-10, Drug Attitude Inventory-10; SWN, Subjective Wellbeing under Neuroleptic Scale; AIMS, Abnormal Involuntary Movement Scale; SAS, Simpson-Angus Scale; BARS, Barnes Akathisia Rating Scale; -, not measured. 
Table 3. Comparisons of characteristics between responders and non-responders

\begin{tabular}{|c|c|c|c|}
\hline Characteristic & Non-responder $(\mathrm{n}=29)$ & Responder $(\mathrm{n}=23)$ & $p$ value \\
\hline Age (yr) & $47.4 \pm 9.6$ & $45.0 \pm 10.3$ & 0.404 \\
\hline Sex, female & $10(34.5)$ & $10(43.5)$ & 0.508 \\
\hline Age of onset (yr) & $31.4 \pm 11.0$ & $27.7 \pm 8.4$ & 0.198 \\
\hline Duration of illness (yr) & $16.0 \pm 9.7$ & $17.3 \pm 8.9$ & 0.612 \\
\hline Total number of hospitalizations & $5.1 \pm 4.7$ & $3.6 \pm 3.8$ & 0.258 \\
\hline \multicolumn{4}{|l|}{ Previous antipsychotics treatment } \\
\hline Monotherapy & $17(58.6)$ & $11(47.8)$ & 0.540 \\
\hline Chlorpromazine equivalent dose (mg/day) & $854.5 \pm 472.0$ & $671.1 \pm 388.7$ & 0.139 \\
\hline \multicolumn{4}{|l|}{ Baseline scores } \\
\hline CGI-S & $4.0 \pm 0.8$ & $4.2 \pm 0.6$ & 0.358 \\
\hline BPRS & $55.1 \pm 9.3$ & $59.0 \pm 9.1$ & 0.138 \\
\hline SOFAS & $42.3 \pm 8.2$ & $34.8 \pm 10.3$ & 0.005 \\
\hline SWN & $71.8 \pm 12.5$ & $67.1 \pm 15.9$ & 0.241 \\
\hline DAI-10 & $5.2 \pm 2.7$ & $5.3 \pm 2.2$ & 0.978 \\
\hline Blonanserin dose during study (mg/day) & $14.7 \pm 4.9$ & $20.4 \pm 3.7$ & $<0.001$ \\
\hline Higher than maintenance dose ( > 16 mg/day) & $15(51.7)$ & $22(95.7)$ & 0.001 \\
\hline
\end{tabular}

Values are presented as mean \pm standard deviation or number (\%).

CGI-S, Clinical Global Impression-Severity; BPRS, Brief Psychiatric Rating Scale; SOFAS, Social and Occupational Functioning Assessment Scale; SWN, Subjective Wellbeing under Neuroleptic Scale; DAI-10, Drug Attitude Inventory-10.

Table 4. Adverse events during study period ( $\geq 3 \%$ )

\begin{tabular}{lc}
\hline \multicolumn{1}{c}{ Adverse event } & $\begin{array}{c}\text { All adverse } \\
\text { events }\end{array}$ \\
\hline $\begin{array}{l}\text { Extrapyramidal symptoms (parkinsonism, dystonia, } \\
\text { tremor) }\end{array}$ & $12(23.1)$ \\
Insomnia & $10(19.2)$ \\
Emotional arousal (anxiety, agitation and excitement) & $6(11.5)$ \\
Constipation/abdominal pain & $6(11.5)$ \\
Cough/upper respiratory infection & $5(9.6)$ \\
Akathisia & $5(9.6)$ \\
Skin rash/itch & $4(7.7)$ \\
Headache & $3(5.8)$ \\
Nausea/vomiting/dyspepsia & $2(3.8)$ \\
\hline
\end{tabular}

Values are presented as number (\%).

$(51.7 \%, \mathrm{n}=15)$. Logistic regression analysis, using age, sex, baseline BPRS and SOFAS scores, and the blonanserin mean dose as covariates, showed that a high mean dose of blonanserin was a significant predictor of the treatment response (odds ratio, $16.744 ; 95 \% \mathrm{Cl}, 1.857-150.983 ; p$ $=0.012$ ).

Eighteen (34.6\%) patients withdrew from the study prematurely: seven $(13.5 \%)$ withdrew their consent, five $(9.6 \%)$ were lost to follow-up, four $(7.7 \%)$ discontinued treatment due to AEs (two cases of akathisia, one case of constipation, and one case of EPS), and two (3.8\%) patients violated the protocol. The AEs frequently reported
( $\geq 3 \%$ ) during the 12-week study period are listed in Table 4. A total of 29 (55.8\%) patients reported 63 AEs. The severity of all reported AEs was mild $(n=48)$ or moderate $(n=15)$. The results of RM-ANOVA showed that the scores on the Simpson-Angus Scale $(\mathrm{F}=1.340, p=$ 0.248), Barnes Akathisia Rating Scale ( $F=0.906, p=$ 0.477), and Abnormal Involuntary Movement Scale (F = 1.623, $p=0.154$; Table 2) did not change significantly during the study period.

\section{Changes in Metabolic Parameters}

In the total study population, $\mathrm{HbA1c}$ was the only metabolic parameter that exhibited a significant change from baseline $(5.4 \pm 0.6 \%)$ to the end of the 12 -week study pe$\operatorname{riod}(5.3 \pm 0.6 \%, p=0.021)$. The serum levels of prolactin and TC also decreased from baseline, but the changes were not statistically significant (Table 5). When the patients were divided into normal and abnormal subgroups according to their baseline values of metabolic parameters, switching to blonanserin significantly improved BW, TC levels, and prolactin levels in the patients with metabolic abnormalities (Table 5). In overweight or obese patients (BMI $\geq 23 \mathrm{~kg} / \mathrm{m}^{2}, \mathrm{n}=33$ ), switching to blonanserin significantly decreased BW from $75.2 \pm 9.3 \mathrm{~kg}$ at baseline to $73.5 \pm 9.2 \mathrm{~kg}$ at week $12(p=0.006)$. The decreases in TC (baseline, $236.1 \pm 47.6 \mathrm{mg} / \mathrm{dl}$; 12 weeks, $209.9 \pm 28.0$ 
Table 5. Changes in metabolic parameters over the 12-week study period

\begin{tabular}{|c|c|c|c|}
\hline Category by baseline value & Baseline & Week 12 & $p$ value \\
\hline \multicolumn{4}{|l|}{$\mathrm{BMI}\left(\mathrm{kg} / \mathrm{m}^{2}\right)$} \\
\hline Total $(n=52)$ & $24.8 \pm 4.0$ & $24.5 \pm 3.6$ & 0.286 \\
\hline Normal $(<23, \mathrm{n}=19)$ & $21.7 \pm 2.1$ & $20.8 \pm 1.7$ & 0.085 \\
\hline Overweight/obesity ( $\geq 23, \mathrm{n}=33$ ) & $26.6 \pm 3.8$ & $26.6 \pm 2.6$ & 0.880 \\
\hline \multicolumn{4}{|l|}{ Weight $(\mathrm{kg})$} \\
\hline Total $(n=52)$ & $68.5 \pm 12.5$ & $67.2 \pm 12.0$ & 0.113 \\
\hline Normal $\left(\mathrm{BMI}<23 \mathrm{~kg} / \mathrm{m}^{2}, \mathrm{n}=19\right)$ & $56.8 \pm 8.0$ & $56.1 \pm 7.6$ & 0.729 \\
\hline Overweight/obesity (BMI $\geq 23 \mathrm{~kg} / \mathrm{m}^{2}, \mathrm{n}=33$ ) & $75.2 \pm 9.3$ & $73.5 \pm 9.2$ & 0.006 \\
\hline \multicolumn{4}{|l|}{ Fasting glucose (mg/dl) } \\
\hline Total $(n=52)$ & $102.7 \pm 32.9$ & $103.6 \pm 28.2$ & 0.774 \\
\hline Normal $(<100, \mathrm{n}=31)$ & $87.6 \pm 8.4$ & $94.8 \pm 18.2$ & 0.144 \\
\hline High $(\geq 100, \mathrm{n}=21)$ & $123.6 \pm 41.9$ & $115.7 \pm 34.8$ & 0.053 \\
\hline \multicolumn{4}{|l|}{ Total cholesterol (mg/dl) } \\
\hline Total $(n=52)$ & $188.8 \pm 53.7$ & $177.6 \pm 38$ & 0.081 \\
\hline Normal $(<200, \mathrm{n}=31)$ & $154.5 \pm 23.2$ & $154.2 \pm 25.0$ & 0.928 \\
\hline High $(\geq 200, n=21)$ & $236.1 \pm 47.6$ & $209.9 \pm 28.0$ & 0.005 \\
\hline \multicolumn{4}{|l|}{ Triglyceride (mg/dl) } \\
\hline Total $(n=52)$ & $149.6 \pm 122.8$ & $140.0 \pm 74.8$ & 0.568 \\
\hline Normal $(<150, \mathrm{n}=38)$ & $100.5 \pm 26.4$ & $117.0 \pm 57.9$ & 0.072 \\
\hline $\operatorname{High}(\geq 150, \mathrm{n}=14)$ & $275.6 \pm 176.5$ & $199.3 \pm 82.5$ & 0.066 \\
\hline \multicolumn{4}{|l|}{ High-density lipoprotein cholesterol (mg/dl) } \\
\hline Total $(n=52)$ & $50.6 \pm 17.1$ & $49.2 \pm 15.4$ & 0.378 \\
\hline Normal ( $\geq 40$ in men, $\geq 50$ in women, $n=33$ ) & $59.9 \pm 14.3$ & $57.7 \pm 12.6$ & 0.373 \\
\hline Low $(<40$ in men, $<50$ in women, $\mathrm{n}=19)$ & $35.4 \pm 8.0$ & $35.3 \pm 7.3$ & 0.936 \\
\hline \multicolumn{4}{|l|}{ Low-density lipoprotein cholesterol (mg/dl) } \\
\hline Total $(n=52)$ & $126.4 \pm 64.8$ & $126.6 \pm 67.1$ & 0.926 \\
\hline Normal $(<130, \mathrm{n}=35)$ & $91.0 \pm 19.6$ & $92.3 \pm 19.5$ & 0.693 \\
\hline $\operatorname{High}(\geq 130, \mathrm{n}=17)$ & $186.7 \pm 70.8$ & $185.2 \pm 78.9$ & 0.345 \\
\hline \multicolumn{4}{|l|}{ Prolactin $(\mathrm{ng} / \mathrm{ml})$} \\
\hline Total $(n=52)$ & $59.0 \pm 78.3$ & $49.1 \pm 77.6$ & 0.064 \\
\hline Normal ( $\leq 18$ in men, $\leq 29$ in women, $\mathrm{n}=19$ ) & $9.5 \pm 4.9$ & $15.8 \pm 11.5$ & 0.123 \\
\hline High ( $>18$ in men, $>29$ in women, $n=33$ ) & $80.0 \pm 85.2$ & $63.2 \pm 88.9$ & 0.003 \\
\hline
\end{tabular}

Values are presented as mean \pm standard deviation.

BMI, body mass index.

$\mathrm{mg} / \mathrm{dl} ; p=0.005)$ and prolactin levels (baseline, $80.0 \pm$ $85.2 \mathrm{ng} / \mathrm{ml} ; 12$ weeks, $63.2 \pm 88.9 \mathrm{ng} / \mathrm{ml} ; p=0.003$ ) over the study period were also significant in patients with hypercholesterolemia (TC $\geq 200 \mathrm{mg} / \mathrm{dl}, \mathrm{n}=21$ ) or hyperprolactinemia (prolactin: $>18 \mathrm{ng} / \mathrm{ml}$ in men, $>29 \mathrm{ng} / \mathrm{ml}$ in women; $n=33$ ). FBS and TG levels also decreased from baseline in the abnormal subgroup, but the differences were not statistically significant $(p=0.053$ and 0.066 , respectively).

\section{DISCUSSION}

To our knowledge, this is the first study to investigate the impact of switching from other antipsychotics to blonanserin in patients with schizophrenia. In the present study, switching to blonanserin caused a decrease in symptoms of schizophrenia and improvements in function, as measured by the SOFAS, and subjective well-being, measured by the SWN. Moreover, switching to blonanserin also improved $\mathrm{HbA} 1 \mathrm{c}$ and some other metabolic and endocrine parameters, including BW, TC levels, and prolactin levels, compared with the baseline values.

The response rate observed in the present study $(44.2 \%)$ was comparable with the results of previous non-switching studies of blonanserin in schizophrenic patients, which reported response rates of $38 \%$ to $49 \%,{ }^{11,22)}$ and switching studies of other antipsychotics, including risperidone, olanzapine, or quetiapine, which reported response rates of approximately $30 \%$ to $50 \%$, ${ }^{23-25)}$ despite differences in the subject characteristics, meas- 
urement scales, and evaluation periods. Moreover, consistent with previous studies of blonanserin, switching to blonanserin was generally well tolerated. There were no serious AEs, and all reported AEs were mild or moderate in severity, with only four $(7.7 \%)$ patients discontinuing the study due to AEs. As reported in a previous review, ${ }^{26)}$ EPS and insomnia were the most frequents AEs. Interestingly, insomnia and emotional arousal, including anxiety, agitation, and excitement, were also reported frequently. These AEs could be due to discontinuation of previous antipsychotics. Discontinuing antipsychotics with strong anticholinergic properties (e.g., olanzapine and quetiapine) may result in insomnia or agitation. ${ }^{27)}$ For example, patients switching from olanzapine to risperidone, which has a similar receptor binding profile to that of blonanserin, were reported to experience withdrawal symptoms, including nausea, vomiting, and agitation. ${ }^{28)}$

In the present study, the clinical benefit of switching to blonanserin was associated with a relatively higher blonanserin mean dose. The response rate was significantly higher in the high-dose group ( $>16 \mathrm{mg} /$ day). In a phase III trial, ${ }^{11)}$ there appeared to be a numerical dose-response for efficacy when using 2.5, 5, and $10 \mathrm{mg}$ /day blonanserin, but the authors did not compare the differences among dosages. In another study, the occupancy of the striatal dopamine $\mathrm{D} 2$ receptor by blonanserin was reported to be $60.8 \%$ at $8 \mathrm{mg}, 73.4 \%$ at $16 \mathrm{mg}$, and $79.7 \%$ at $24 \mathrm{mg}^{29)}$ Therefore, the results from this study were not surprising, in that approximately $70 \%$ to $80 \%$ of striatal D2 receptor occupancy was required for antipsychotic response. ${ }^{30,31)}$

In the present study, there were improvements in $\mathrm{HbA} 1 \mathrm{c}$ in the total patient population and in BW and TC in subjects with abnormal metabolic parameter values at baseline. Although little information is available regarding the effects of blonanserin on metabolic parameters, blonanserin has minimal potential for inducing weight gain and metabolic abnormalities due to its low affinity for serotonin 5-HT2C, histamine $\mathrm{H} 1$, and muscarinic M1 receptors. ${ }^{8)}$ In a meta-analysis of four studies involving 1,080 schizophrenic patients, ${ }^{32)}$ there were no significant differences in TC, TG, FBS, or HbA1c levels in patients treated with blonanserin versus antipsychotics, including haloperidol and risperidone. However, blonanserin induced less BW gain compared with risperidone. Furthermore, a recent network meta-analysis indicated that blonanserin was the most BW-neutral antipsychotic, with even less effect on BW than aripiprazole. ${ }^{33)}$ As positive effects can be achieved when switching treatment from metabolically disruptive antipsychotics to more BW-neutral antipsychotics, ${ }^{27)}$ the results of the present study suggest other benefits of switching to blonanserin from other antipsychotics that have a high to moderate risk of inducing metabolic abnormalities, including olanzapine, quetiapine, and risperidone.

The improvement in hyperprolactinemia, which is associated with sexual dysfunction, bone loss, and increased cancer risks, ${ }^{34,35)}$ observed in this study was also consistent with previous reports. ${ }^{10,36,37)}$ Blonanserin shows a relatively high brain/plasma concentration ratio ( $\mathrm{B} / \mathrm{P}$ ratio), which is a good biomarker of antipsychoticinduced hyperprolactinemia. ${ }^{29,36)}$ The $\mathrm{B} / \mathrm{P}$ ratio indicates the ability of antipsychotics to penetrate the blood-brain barrier, and a high B/P ratio indicates a lower concentration of antipsychotics at the pituitary receptor site than at the cerebral cortex receptor site. ${ }^{38)}$ This is thought to be because blonanserin is not a substrate for P-glycoprotein, which actively transports substrates from the brain to the blood across the blood-brain barrier and limits drug entry into the central nervous system. ${ }^{39)}$ These findings may explain why the plasma prolactin level was less affected by blonanserin than by other antipsychotics, and support the rationale that blonanserin is a suitable alternative for schizophrenic patients developing antipsychotic-induced hyperprolactinemia.

This study had several limitations, including its small sample size. In addition, this study did not include a control group and was not randomized or blinded. Due to the lack of a control group, the efficacy and tolerability of blonanserin observed in this study cannot be compared with those of other antipsychotic drugs. Due to the small sample size, we could not analyze the effects of previously used antipsychotics to determine whether switching to blonanserin from other antipsychotics would have beneficial effects on psychopathology, tolerability, metabolic, or endocrine parameters. Second, the 2-week tapering-off period applied in our study may be too abrupt to avoid withdrawal symptoms from the previous antipsychotics. Other switching strategies, such as plateau cross-tapering, in which the new antipsychotic is slowly uptitrated with discontinuation of the previous antipsychotic after reaching the therapeutic dosage of the new antipsychotic, or descending taper switch, in which the previous anti- 
psychotic is gradually discontinued and the new one abruptly started at the therapeutic dose, would be more appropriate to exclude potential withdrawal/discontinuing effects of the previous antipsychotic. ${ }^{27,40)}$ Third, we did not investigate the use of concomitant medications other than benzodiazepines. Therefore, we cannot exclude the possibility that the use of anticholinergics, propranolol, or hypnotics affected the results. In addition, the timing of blonanserin administration was not recorded. As food intake significantly affects the bioavailability of blonanserin, ${ }^{8)}$ standardization of the administration timing would allow greater confidence in the results.

In summary, the results of the present study suggested that switching to blonanserin is effective and well-tolerated in patients with schizophrenia who had an insufficient treatment response to other antipsychotics, and it may show additional beneficial effects in terms of improving metabolic and endocrine parameters. Blonanserin appears to be a good treatment option for patients with schizophrenia experiencing an insufficient response to a previous antipsychotic or suffering from metabolic or endocrine AEs. However, the results of the present study are insufficient to derive conclusive clinical recommendations because of the limitations in the methods. Adequately designed, large, double-blind, placebo-controlled, randomized clinical trials are needed to address the usefulness of blonanserin switching in schizophrenic patients.

\section{- Acknowledgments}

This study was supported by the Bukwang Pharmaceutical Company, Ltd., Korea. The Bukwang Pharmaceutical Company had no further role in the study design; in the collection, analysis, or interpretation of data; in the writing of the report; or in the decision to submit the paper for publication.

\section{Conflicts of Interest}

No potential conflict of interest relevant to this article was reported.

\section{REFERENCES}

1. Heilbronner U, Samara M, Leucht S, Falkai P, Schulze TG. The longitudinal course of schizophrenia across the lifespan: clinical, cognitive, and neurobiological aspects. Harv Rev Psychiatry 2016;24:118-128.
2. Tripathi A, Kar SK, Shukla R. Cognitive deficits in schizophrenia: understanding the biological correlates and remediation strategies. Clin Psychopharmacol Neurosci 2018; 16:7-17.

3. Kirkpatrick B, Fenton WS, Carpenter WT Jr, Marder SR. The NIMH-MATRICS Consensus statement on negative symptoms. Schizophr Bull 2006;32:214-219.

4. De Hert M, van Winkel R, Wampers M, Kane J, van Os J, Peuskens J. Remission criteria for schizophrenia: evaluation in a large naturalistic cohort. Schizophr Res 2007;92:68-73.

5. Remington G, Addington D, Honer W, Ismail Z, Raedler T, Teehan M. Guidelines for the pharmacotherapy of schizophrenia in adults. Can J Psychiatry 2017;62:604-616.

6. National Collaborating Centre for Mental Health. Psychosis and schizophrenia in adults: treatment and management. London:National Institute for Health and Care Excellence (UK);2014.

7. Miyamoto S, Duncan GE, Marx CE, Lieberman JA. Treatments for schizophrenia: a critical review of pharmacology and mechanisms of action of antipsychotic drugs. Mol Psychiatry 2005; 10:79-104.

8. Tenjin T, Miyamoto S, Ninomiya Y, Kitajima R, Ogino S, Miyake $\mathrm{N}$, et al. Profile of blonanserin for the treatment of schizophrenia. Neuropsychiatr Dis Treat 2013;9:587-594.

9. Miura S. Clinical evaluation of blonanserin for schizophrenia: a randomized controlled study comparing blonanserin with risperidone. Jpn J Clin Psychopharmacol 2008; 11:297-314.

10. Yang J, Bahk WM, Cho HS, Jeon YW, Jon DI, Jung HY, et al. Efficacy and tolerability of blonanserin in the patients with schizophrenia: a randomized, double-blind, risperidonecompared trial. Clin Neuropharmacol 2010;33:169-175.

11. Garcia E, Robert M, Peris F, Nakamura H, Sato N, Terazawa Y. The efficacy and safety of blonanserin compared with haloperidol in acute-phase schizophrenia: a randomized, double-blind, placebo-controlled, multicentre study. CNS Drugs 2009;23:615-625.

12. Murasaki M. Clinical evaluation of blonanserin for schizophrenia: a double-blind trial comparing blonanserin with haloperidol. Jpn J Clin Psychopharmacol 2007;10:20592079.

13. Woo YS, Park JE, Kim DH, Sohn I, Hwang TY, Park YM, et al. Blonanserin augmentation of atypical antipsychotics in patients with schizophrenia-who benefits from blonanserin augmentation?: an open-label, prospective, multicenter study. Psychiatry Investig 2016;13:458-467.

14. Kishi T, Matsuda Y, Nakamura H, Iwata N. Blonanserin for schizophrenia: systematic review and meta-analysis of double-blind, randomized, controlled trials. I Psychiatr Res 2013;47:149-154.

15. Takaki M, Okahisa Y, Kodama M, Mizuki Y, Sakamoto S, Ujike $\mathrm{H}$, et al. Efficacy and tolerability of blonanserin in 48 patients with intractable schizophrenia. Acta Neuropsychiatr 2012;24:380-383. 
16. Andrade C. Cardiometabolic risks in schizophrenia and directions for intervention, 1: magnitude and moderators of the problem. J Clin Psychiatry 2016;77:e844-e847.

17. Weiden PJ, Miller AL, Lambert TJ, Buckley PF. The art and science of switching antipsychotic medications, part 2. J Clin Psychiatry 2007;68:e02.

18. Kim Y, Wang SM, Kwak KP, Yoon HK, Pae CU, Kim JJ, et al. Amisulpride switching in schizophrenic patients who showed suboptimal effect and/or tolerability to current antipsychotics in a naturalistic setting: an explorative study. Clin Psychopharmacol Neurosci 2016;14:371-377.

19. Naber D. A self-rating to measure subjective effects of neuroleptic drugs, relationships to objective psychopathology, quality of life, compliance and other clinical variables. Int Clin Psychopharmacol 1995;10 Supp/ 3:133-138.

20. Hogan TP, Awad AG, Eastwood R. A self-report scale predictive of drug compliance in schizophrenics: reliability and discriminative validity. Psychol Med 1983;13:177-183.

21. Gardner DM, Murphy AL, O'Donnell H, Centorrino F, Baldessarini RJ. International consensus study of antipsychotic dosing. Am J Psychiatry 2010;167:686-693.

22. Kishi T, Matsuda Y, Fujita K, Iwata N. Early prediction of blonanserin response in Japanese patients with schizophrenia. Neuropsychiatr Dis Treat 2014;10:1861-1866.

23. Takahashi $\mathrm{H}$, Kamata M, Yoshida K, Ishigooka J, Higuchi $\mathrm{H}$. Switching to olanzapine after unsuccessful treatment with risperidone during the first episode of schizophrenia: an openlabel trial. J Clin Psychiatry 2006;67:1577-1582.

24. Takahashi H, Yoshida K, Ishigooka J, Higuchi H. Switching to risperidone after unsuccessful treatment of olanzapine in the first-episode schizophrenia: an open trial. Prog Neuropsychopharmacol Biol Psychiatry 2006;30:1067-1072.

25. Suzuki T, Uchida H, Watanabe K, Nomura K, Takeuchi $\mathrm{H}$, Tomita $\mathrm{M}$, et al. How effective is it to sequentially switch among olanzapine, quetiapine and risperidone?--a randomized, open-label study of algorithm-based antipsychotic treatment to patients with symptomatic schizophrenia in the real-world clinical setting. Psychopharmacology (Berl) 2007; 195:285-295.

26. Deeks ED, Keating GM. Blonanserin: a review of its use in the management of schizophrenia. CNS Drugs 2010;24:65-84.

27. Cerovecki A, Musil R, Klimke A, Seemüller F, Haen E, Schennach $\mathrm{R}$, et al. Withdrawal symptoms and rebound syndromes associated with switching and discontinuing atypical antipsychotics: theoretical background and practical recommendations. CNS Drugs 2013;27:545-572.

28. Ganguli R, Brar JS, Mahmoud R, Berry SA, Pandina GJ. Assessment of strategies for switching patients from olanzapine to risperidone: a randomized, open-label, rater-blinded study. BMC Med 2008;6:17.

29. Tateno A, Arakawa R, Okumura M, Fukuta H, Honjo K,
Ishihara K, et al. Striatal and extrastriatal dopamine D2 receptor occupancy by a novel antipsychotic, blonanserin: a PET study with [11C]raclopride and [11C]FLB 457 in schizophrenia. J Clin Psychopharmacol 2013;33:162-169.

30. Kapur S, Zipursky R, Jones C, Remington G, Houle S. Relationship between dopamine D(2) occupancy, clinical response, and side effects: a double-blind PET study of first-episode schizophrenia. Am J Psychiatry 2000;157:514-520.

31. Uchida H, Mamo DC, Kapur S, Labelle A, Shammi C, Mannaert EJ, et al. Monthly administration of long-acting injectable risperidone and striatal dopamine D2 receptor occupancy for the management of schizophrenia. JClin Psychiatry 2008;69:1281-1286.

32. Kishi T, Matsuda Y, Iwata N. Cardiometabolic risks of blonanserin and perospirone in the management of schizophrenia: a systematic review and meta-analysis of randomized controlled trials. PLoS One 2014;9:e88049.

33. Kishi T, Ikuta T, Matsunaga S, Matsuda Y, Oya K, Iwata N. Comparative efficacy and safety of antipsychotics in the treatment of schizophrenia: a network meta-analysis in a Japanese population. Neuropsychiatr Dis Treat 2017;13:1281-1302.

34. Hatano M, Kamei H, Kato A, Takeuchi I, Hanya M, Uno J, et al. Assessment of the latent adverse events of antipsychotic treatment using a subjective questionnaire in Japanese patients with schizophrenia. Clin Psychopharmacol Neurosci 2017;15:132-137.

35. Ajmal A, Joffe H, Nachtigall LB. Psychotropic-induced hyperprolactinemia: a clinical review. Psychosomatics 2014;55: 29-36.

36. Kawabe K, Horiuchi F, Ueno S. Blonanserin, a novel antipsychotic, is suitable for treating schizophrenia associated with hyperprolactinemia: a case series. Clin Neuropharmacol 2013;36:239-241.

37. Kishi T, Matsui Y, Matsuda Y, Katsuki A, Hori H, Yanagimoto $\mathrm{H}$, et al. Efficacy, tolerability, and safety of blonanserin in schizophrenia: an updated and extended systematic review and meta-analysis of randomized controlled trials. Pharmacopsychiatry 2019;52:52-62.

38. Arakawa R, Okumura M, Ito $\mathrm{H}$, Takano A, Takahashi $\mathrm{H}$, Takano $\mathrm{H}$, et al. Positron emission tomography measurement of dopamine $D(2)$ receptor occupancy in the pituitary and cerebral cortex: relation to antipsychotic-induced hyperprolactinemia. J Clin Psychiatry 2010;71:1131-1137.

39. Inoue T, Osada K, Tagawa M, Ogawa Y, Haga T, Sogame Y, et al. Blonanserin, a novel atypical antipsychotic agent not actively transported as substrate by P-glycoprotein. Prog Neuropsychopharmacol Biol Psychiatry 2012;39:156-162.

40. Murru A, Hidalgo D, Bernardo M, Bobes J, Saiz-Ruiz J, Álamo C, et al. Antipsychotic switching in schizoaffective disorder: a systematic review. World J Biol Psychiatry 2016;17:495-513. 